\title{
Infrared Multiple Photon Dissociation Action Spectroscopy and Theoretical Studies of Triethyl Phosphate Complexes: Effects of Protonation and Sodium Cationization on Structure
}

\author{
B. S. Fales, ${ }^{1}$ N. O. Fujamade, ${ }^{1}$ J. Oomens, ${ }^{2,3}$ M. T. Rodgers ${ }^{1}$ \\ ${ }^{1}$ Department of Chemistry, Wayne State University, Detroit, MI, USA \\ ${ }^{2}$ FOM Institute for Plasma Physics Rijnhuizen, Nieuwegein, The Netherlands \\ ${ }^{3}$ van't Hoff Institute for Molecular Sciences, University of Amsterdam, Amsterdam, The Netherlands
}

\begin{abstract}
The gas-phase structures of protonated and sodium cationized complexes of triethyl phosphate, $[T E P+\mathrm{H}]^{+}$and $\left[T E P+\mathrm{Na}^{+}\right.$, are examined via infrared multiple photon dissociation (IRMPD) action spectroscopy using tunable IR radiation generated by a free electron laser, a Fourier transform ion cyclotron resonance mass spectrometer with an electrospray ionization source, and theoretical electronic structure calculations. Measured IRMPD action spectra are compared to linear IR spectra calculated at the B3LYP/6-31 G(d,p) level of theory to identify the structures accessed in the experimental studies. For comparison, theoretical studies of neutral TEP are also performed. Sodium cationization and protonation produce changes in the central phosphate geometry, including an increase in the alkoxy $\angle \mathrm{OPO}$ bond angle and shortening of the alkoxy $\mathrm{P}-\mathrm{O}$ bond. Changes associated with protonation are more pronounced than those produced by sodium cationization.
\end{abstract}

Key words: Triethyl phosphate, Free electron laser, Infrared multiple photon dissociation, Protons, Sodium cations

\section{Introduction}

as phase infrared multiple photon dissociation (IRMPD) action spectroscopy has proven to be a useful tool for the elucidation of structural information for a variety of chemical systems, especially large, biologically relevant molecules [1-13]. Previous attempts to describe such complexes in solution proved difficult, as solvent effects are notoriously difficult to account for, and the size of

Electronic supplementary material The online version of this article (doi:10.1007/s13361-011-0208-7) contains supplementary material, which is available to authorized users.

Correspondence to: M. T. Rodgers; e-mail: mrodgers@chem.wayne.edu the complexes made ionization problematic prior to the advent of appropriate ionization methods. Soft ionization techniques, such as matrix assisted laser desorption ionization (MALDI) and electrospray ionization (ESI), are effective at reliably producing ions from very large and delicate molecules [14, 15]. Subsequent selection and trapping of ions can be achieved using a variety of methods, including Penning-type Fourier transform ion cyclotron resonance (FT-ICR) and Paul-type quadrupole trapping [4]. Once a sufficient population of ions has been collected in the trap, high intensity light from a source such as a free electron laser (FEL) or a neodymium-doped yttrium aluminum garnet (Nd:YAG) pumped optical parametric oscillator/ amplifier (OPO/OPA) laser system is used to introduce radiation to the trap. The infrared region is scanned, 
resulting in vibrational excitation and dissociation of the analyte ions [16-19]. Ion yield can be plotted versus the frequency of the activating radiation to produce an IRMPD action spectrum.

IRMPD methods are especially powerful when used in conjunction with computational techniques. Action spectroscopy studies serve to verify the accuracy of theoretical methods through comparison of predicted linear IR spectra with observed IRMPD spectra. Computed structures corresponding to the experimental spectra, supported by single point energy calculations, can provide useful geometric and energetic data for the complexes investigated [4]. A high degree of correlation between predicted IR and observed IRMPD spectra results in a high level of confidence in the utility of the theoretical methods, making these two techniques highly complementary and mutually supportive.

While the previously described experimental methods work well to investigate relatively large molecules, theoretical parameters for macromolecular systems such as proteins and nucleic acids are still far too complex to accurately calculate in the solution phase. Instead, smaller, more manageable complexes can be chosen to represent critical regions of the overall system, acting as useful models that can be used to probe and understand various features of macroscopic structure. Interactions within proteins are often studied in terms of constituent amino acids and small peptides, as demonstrated by recent work done in a variety of labs, including our own [20-36]. Similarly, nucleic acids are conveniently broken down into their component nucleobases, nucleotides, nucleosides, and phosphate ester derivatives. Recently, work has been completed to this end in our laboratory, using a variety of model systems that include diethyl phosphate (DEP) [37], triethyl phosphate (TEP) [38, 39], trimethyl phosphate [40], and uracil and substituted uracils [41-46] using both threshold collision-induced dissociation (TCID) and IRMPD techniques.

While DEP and di-isopropyl phosphate are excellent model systems for the primary and secondary alkyl phosphate linkages, respectively, found in nucleic acids, TEP is also a suitable model for the primary alkyl phosphate linkage. In addition, a variety of nucleic acid alkylations have been reported that produce phosphotriesters [47-49]. Typically, these types of modifications are mutagenic in nature, or are artificially induced to enable strand breakage for the express purpose of anticancer and tumor repressor therapies. Following phosphotriester formation, base-induced hydrolysis is the proposed mode of nucleic acid chain cleavage. While mechanisms have been proposed and supported for these reactions [48, 49], energetics and precise structural information have yet to be thoroughly investigated.

In addition to its use as a simple model of phosphate esters found in nucleotides and nucleic acid chains, TEP is a strong Lewis base prized for its ability to extract U(VI) and $\mathrm{Pu}(\mathrm{IV})$ from nitric acid that has been obtained from spent nuclear fuel rods $[50,51]$. In the work of Groenewold et al. [50], potassium cationized TEP was investigated using methods similar to those employed in the current work. By examining the effects of protonation and sodium cationization on the relative energies and overall structure of TEP, we can more thoroughly understand the effects of changing proton and sodium cation concentrations in the local environment of nucleic acid chains. While results of this study are but one small piece of a much larger puzzle, they provide important data that can be used for future elucidation of biochemical mechanisms, advances in the development and understanding of pharmacologic compounds relating to genetic disease processes, and an overall improvement in our understanding of low-level genetic regulatory mechanisms.

\section{Experimental}

\section{General Procedures}

A 4.7 $\mathrm{T}$ Fourier transform ion cyclotron resonance mass spectrometer (FT-ICR MS), coupled to the free electron laser for infrared experiments (FELIX), was used in these experiments and has previously been described in detail elsewhere [16-19]. Triethyl phosphate was obtained from Sigma-Aldrich (Zwijndrecht, Netherlands). Solutions containing $1 \mathrm{mM}$ TEP were prepared in a 50:50 methanol:water mixture. The sodiated complex, $[\mathrm{TEP}+\mathrm{Na}]^{+}$was generated by adding $1 \mathrm{mM}$ sodium chloride to the TEP solution. Protonated TEP ions, $[\mathrm{TEP}+\mathrm{H}]^{+}$, were generated by adding $1 \mathrm{mM} \mathrm{HCl}$ to the TEP solutions. The TEP solutions were introduced into the mass spectrometer using a Micromass (Waters S.A.S., En Yvelines Cedex, France) electrospray ionization (ESI) source. Ions were collected for several seconds in a hexapole trap before being transferred into the ICR cell via a quadrupole deflector and an octopole ion guide. Precursor ions were selected using stored waveform inverse Fourier transform (SWIFT) methods prior to irradiation by FEL light in the first stage of tandem MS. The selected precursor ions were irradiated for $2-3 \mathrm{~s}$ over the range of wavelengths (frequencies) extending from $\sim 16.50$ to $5.7 \mu \mathrm{m}$ $\left(\sim 600\right.$ to $\left.1750 \mathrm{~cm}^{-1}\right)$. The IRMPD fragmentation of [TEP $\left.+\mathrm{H}\right]^{+}$ was efficient enough that irradiation for only $2 \mathrm{~s}$ was necessary, while the sodiated complex, $[\text { TEP }+\mathrm{Na}]^{+}$, required $3 \mathrm{~s}$ irradiation to produce IRMPD spectra of similar quality $(\mathrm{S} / \mathrm{N})$.

\section{Theoretical Calculations}

Representative model structures were obtained for TEP, $[\text { TEP }+\mathrm{H}]^{+}$, and $[\text {TEP }+\mathrm{Na}]^{+}$using simulated annealing molecular mechanics procedures employing the $\mathrm{MM}+$ force field and ab initio calculations. Potential low-energy candidate structures were obtained via a 300 cycle annealing process using HyperChem [52] software. A three phase annealing process was used, with each cycle beginning and ending at $0 \mathrm{~K}$, lasting for $0.8 \mathrm{ps}$, and achieving a simulation temperature of $1000 \mathrm{~K}$. Heating and cooling times for each cycle were $0.3 \mathrm{ps}$ each, allowing $0.2 \mathrm{ps}$ for the complex to sample conformational space at the simulation temperature. Relative energies were computed using molecular mechanics 
methods every 0.001 ps. The most stable conformers accessed at the end of each annealing cycle were subjected to additional analysis. For each complex, between seven and 25 of the most stable conformers found via the simulated annealing procedure and encompassing the entire range of structures found were further investigated using density functional theory (DFT) methods. Geometry optimizations, frequency analyses, and single point energy calculations were performed using the Gaussian 03 suite of programs [53]. Initial optimizations were performed at the B3LYP/6$31 \mathrm{G}(\mathrm{d})$ level of theory. However, calculations using a larger basis set, i.e., B3LYP/6-31G(d,p), were found to provide slightly improved agreement with the experimental IRMPD spectroscopic data, and resulted in negligible changes in the relative energetics of the various stable conformers computed. The best fits to the experimental results for the $[\mathrm{TEP}+\mathrm{H}]^{+}$and $[\mathrm{TEP}+\mathrm{Na}]^{+}$complexes were found when the frequencies were unscaled. The theoretical linear IR spectra were broadened using a $30 \mathrm{~cm}^{-1} \mathrm{FWHM}$ Gaussian line shape to account for the effects of multiple photon excitation and to allow for meaningful comparison to the experimental spectra. Single point energy calculations were carried out at the B3LYP, B3P86, and MP2(full) levels of theory using the 6-311 $+\mathrm{G}(2 \mathrm{~d}, 2 \mathrm{p})$ basis set. Energetic data include zero point energy (ZPE) corrections for the single point energy calculations and Gibbs energy corrections for the free energy values [based on the frequencies computed at the B3LYP/6-31G(d,p) level]. The groundstate structure of each complex was determined by comparing the relative energies of each of the stable conformers computed, taking the lowest energy structure as that of the ground state.

\section{Results}

\section{IRMPD Action Spectra}

FEL activation of phosphate ester complexes produced spectra using IRMPD yield methods according to Equation (1),

$$
\operatorname{IRMPD} \text { yield }=\left(\sum \mathrm{I}_{\mathrm{f}}\right) /\left(\mathrm{I}_{\mathrm{p}}+\sum \mathrm{I}_{\mathrm{f}}\right)
$$

where $I_{p}$ is the precursor ion intensity, $I_{f}$ is the fragment ion intensity, and the summation is over all fragment ions. Figure 1 depicts IRMPD activity in the $700-1450 \mathrm{~cm}^{-1}$ range for each of the cationized TEP complexes. Three loss channels were observed for $[\mathrm{TEP}+\mathrm{H}]^{+}$, corresponding to sequential loss of neutral ethene molecules at $\mathrm{m} / z=155$ (loss of $\mathrm{C}_{2} \mathrm{H}_{4}$ ), $m / z=127$ (loss of two $\mathrm{C}_{2} \mathrm{H}_{4}$ ), and $m / z=99$ (loss of three $\mathrm{C}_{2} \mathrm{H}_{4}$ ). In contrast, only a single fragmentation channel corresponding to loss of the intact TEP ligand was seen in the $[\mathrm{TEP}+\mathrm{Na}]^{+}$complex, resulting in detection of $\mathrm{Na}^{+}$at $m / z=23$. No products arising from activation of the phosphate ester linkages were observed, consistent with previous CID studies of the [TEP $+\mathrm{Na}]^{+}$complex [38].

Several high intensity bands are visible in the $[\mathrm{TEP}+\mathrm{H}]^{+}$ spectrum. The three most prominent peaks are located at

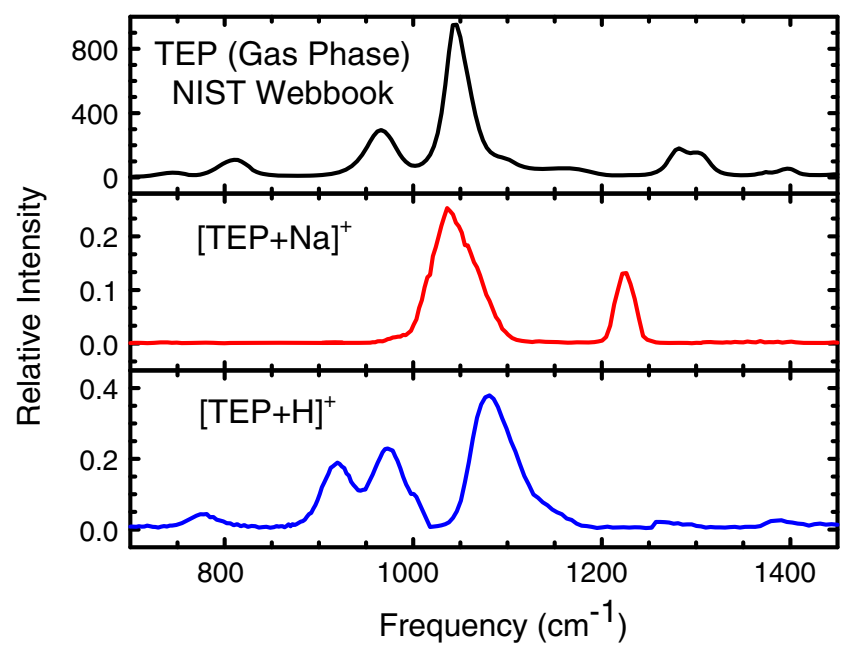

Figure 1. Gas phase IR spectrum of neutral TEP taken from the NIST spectral database [55] and measured IRMPD action spectra of the $[\mathrm{TEP}+\mathrm{H}]^{+}$and $[\mathrm{TEP}+\mathrm{Na}]^{+}$complexes

1080,975 , and $920 \mathrm{~cm}^{-1}$. The least intense feature of these three, the $920 \mathrm{~cm}^{-1}$ band, is $\sim 80 \%$ as intense as the $975 \mathrm{~cm}^{-1}$ band, and roughly half the intensity of the $1080 \mathrm{~cm}^{-1}$ band. A relatively weak band is visible at $780 \mathrm{~cm}^{-1}$, and prominent shoulders are present at 1002 and $1130 \mathrm{~cm}^{-1}$. What initially appear to be low intensity bands at 1260 and $1390 \mathrm{~cm}^{-1}$ are most likely the result of baseline noise in the high energy region. While a variety of spectral features are present in the protonated TEP system, only two major features are visible in the $[\mathrm{TEP}+\mathrm{Na}]^{+}$spectrum. A high intensity band at $1038 \mathrm{~cm}^{-1}$ dominates the spectrum, and is accompanied by a second band at $1225 \mathrm{~cm}^{-1}$ that is roughly half the intensity and half the width of the band at $1038 \mathrm{~cm}^{-1}$.

\section{Theoretical Results}

In addition to complementary theoretical studies to the cationic $[\text { TEP }+\mathrm{Na}]^{+}$and $[\text {TEP }+\mathrm{H}]^{+}$systems investigated experimentally, neutral TEP structures, energies, and spectra were investigated for comparative purposes. Relative energies (at $0 \mathrm{~K}$ ) and free energies (at $298 \mathrm{~K}$ ) of the most stable conformers are listed in Table 1. Linear IR spectra obtained from the theoretical calculations are compared to the experimental IRMPD action spectra.

\section{TEP}

A total of five conformers were found within $5 \mathrm{~kJ} / \mathrm{mol}$ (MP2) of the ground-state structure as shown in Figure 2 and Figure 1S of the Supplementary Information. Each conformer differs slightly in the spatial arrangement of the alkoxy chains about the central phosphate moiety. The central phosphate group retains a nearly tetrahedral arrangement for each conformer, with only minor variations in $\angle \mathrm{OPO}$ bond angles and $\mathrm{P}-\mathrm{O}$ bond lengths observed. As might be expected, the alkoxy side chains adopt a fully 
Table 1. Relative Energies at $0 \mathrm{~K}$ and Free Energies at $298 \mathrm{~K}$ of Various Stable Low-Energy Geometries of TEP Complexes ${ }^{\mathrm{a}}$

\begin{tabular}{|c|c|c|c|c|c|c|c|}
\hline \multirow[t]{2}{*}{ Species } & \multirow[t]{2}{*}{ Conformer } & \multicolumn{2}{|c|}{ B3LYP } & \multicolumn{2}{|c|}{ В3Р86 } & \multicolumn{2}{|c|}{ MP2(full) } \\
\hline & & $\Delta \mathrm{H}_{0}$ & $\Delta \mathrm{G}_{298}$ & $\Delta \mathrm{H}_{0}$ & $\Delta \mathrm{G}_{298}$ & $\Delta \mathrm{H}_{0}$ & $\Delta \mathrm{G}_{298}$ \\
\hline \multirow[t]{5}{*}{ TEP } & $\mathrm{C} 1$ & 0.0 & 0.0 & 0.0 & 0.0 & 0.0 & 0.0 \\
\hline & $\mathrm{C} 2$ & 2.4 & 1.9 & 2.0 & 1.4 & 0.8 & 0.2 \\
\hline & $\mathrm{C} 3$ & 4.8 & 4.9 & 4.7 & 4.8 & 2.4 & 2.6 \\
\hline & $\mathrm{C} 4$ & 5.9 & 7.7 & 4.9 & 6.6 & 2.8 & 4.5 \\
\hline & C5 & 5.4 & 7.7 & 4.5 & 6.8 & 2.7 & 5.0 \\
\hline \multirow[t]{4}{*}[\mathrm{TEP}+\mathrm{H}]{$^{+}$} & $\mathrm{C} 1$ & 0.0 & 0.0 & 0.0 & 0.0 & 0.0 & 0.0 \\
\hline & $\mathrm{C} 2$ & 3.4 & 5.6 & 2.9 & 5.2 & 1.8 & 4.0 \\
\hline & $\mathrm{C} 3$ & 6.5 & 9.6 & 5.7 & 8.8 & 4.1 & 7.2 \\
\hline & $\mathrm{C} 4$ & 17.6 & 17.8 & 17.1 & 17.3 & 16.3 & 16.4 \\
\hline \multirow[t]{3}{*}[\mathrm{TEP}+\mathrm{Na}]{$^{+}$} & $\mathrm{B} 1$ & 0.0 & 0.0 & 0.0 & 0.0 & 0.0 & 0.0 \\
\hline & B2 & 2.8 & 2.4 & 2.4 & 2.0 & 1.9 & 1.5 \\
\hline & M1 & 9.5 & 4.2 & 10.1 & 4.9 & 12.5 & 7.2 \\
\hline
\end{tabular}

${ }^{a}$ Energetics determined from single point energies calculated at the B3LYP/6-311 + G(2d,2p) level of theory using structures optimized at the B3LYP/6-31 G $(\mathrm{d}, \mathrm{p})$ level of theory and including zero point energy corrections. All energies are reported in $\mathrm{kJ} / \mathrm{mol}$

staggered arrangement around the central phosphate in the ground-state structure, $\mathrm{C} 1$, resulting in the most symmetric and least strained of all conformers computed here. Rotation

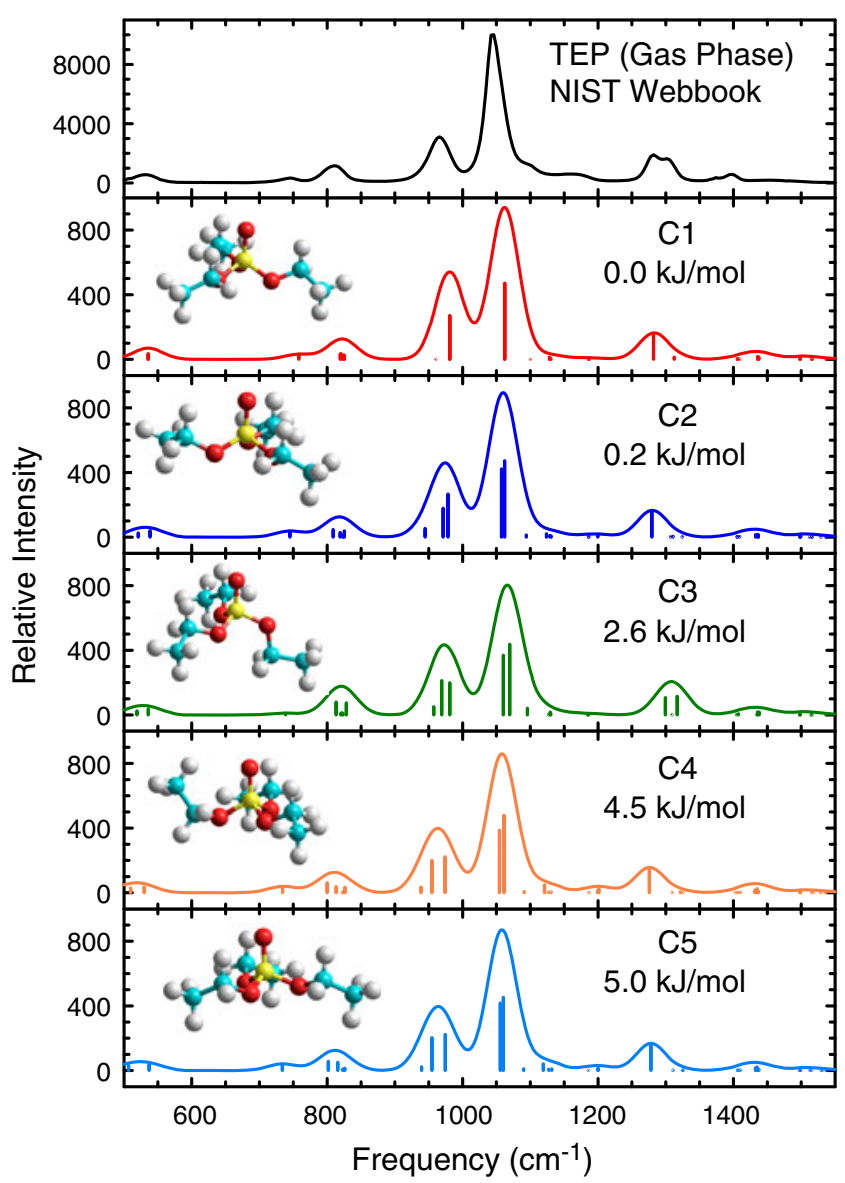

Figure 2. Comparison of the gas phase IR spectrum of TEP taken from the NIST spectral database [55] to the linear IR spectra predicted for the five most stable conformers of neutral TEP at the B3LYP/6-31 G(d,p) level of theory. The structures and MP2(full)/6-311 + G(2d,2p) relative free energies of each conformer are also shown of a single alkoxy chain about the $\angle \mathrm{POCC}$ dihedral angle by $\sim 166.9^{\circ}$ produces the $\mathrm{C} 2$ structure at a cost of only $0.2 \mathrm{~kJ} / \mathrm{mol}$ (MP2) due to increased torsional strain. Rotation of $\sim 133.9^{\circ}$ about the $\angle \mathrm{OPOC}$ dihedral angle of the $\mathrm{C} 1$ structure produces the $\mathrm{C} 3$ structure, lying $2.6 \mathrm{~kJ} / \mathrm{mol}$ higher in free energy (MP2). Additional geometric modifications to the alkoxy side chains in the $\mathrm{C} 4$ and $\mathrm{C} 5$ structures produce conformers of increasing energy due to both torsional and steric contributions, lying 4.5 and $5.0 \mathrm{~kJ} / \mathrm{mol}$ (MP2) above the $\mathrm{C} 1$ conformer, respectively.

$[\mathrm{TEP}+\mathrm{H}]^{+}$

A thorough search of conformational space reveals four relatively low-energy conformers of $[\mathrm{TEP}+\mathrm{H}]^{+}$that involve binding of the proton to the oxo oxygen atom with $\mathrm{H}^{+}-\mathrm{OP}$ bond distances of $0.971 \AA$, as shown in Figure 3 and Figure $2 \mathrm{~S}$ of the Supplementary Information. In these complexes, additional stabilization of the proton may be provided by interaction with the alkoxy oxygen atom(s). However, the closest alkoxy oxygen atom is at least $2.6 \AA$ away and the $\angle \mathrm{COH}$ bond angles do not provide an ideal orientation for hydrogen bond stabilization (i.e., linear), such that only very minor stabilization occurs. Similar to the neutral complex, the different conformers arise as a result of varying the spatial orientation of the alkoxy side chains around the roughly tetrahedral phosphate moiety. Conformers $\mathrm{C} 1, \mathrm{C} 2$, and $\mathrm{C} 3$ all share similar geometric features, and as a result these conformers lie within $10 \mathrm{~kJ} / \mathrm{mol}$ of each other. $\mathrm{C} 1$, the ground-state conformer, has staggered alkoxy side chains, with the side chain adjacent to the hydroxyl oxygen atom oriented down and away from the $\mathrm{P}=\mathrm{O}$ oxo moiety with an $\angle \mathrm{OPOC}$ dihedral angle of $167.6^{\circ}$. The orientation of the proton leads to an $\angle \mathrm{H}^{+} \mathrm{OPO}$ dihedral angle of $38.8^{\circ}$ for the adjacent alkoxy group with an $\mathrm{H}^{+}-\mathrm{OC}$ distance of $2.631 \AA$ and an $\angle \mathrm{H}^{+} \mathrm{OC}$ angle of $157.9^{\circ}$. Conformers $\mathrm{C} 2$ and $\mathrm{C} 3$ also share this characteristic downward rotation of the alkoxy side chain with very similar $\angle \mathrm{OPOC}$ and $\angle \mathrm{H}^{+} \mathrm{OPO}$ dihedral angles and $\mathrm{H}^{+}-\mathrm{OC}$ dis- 


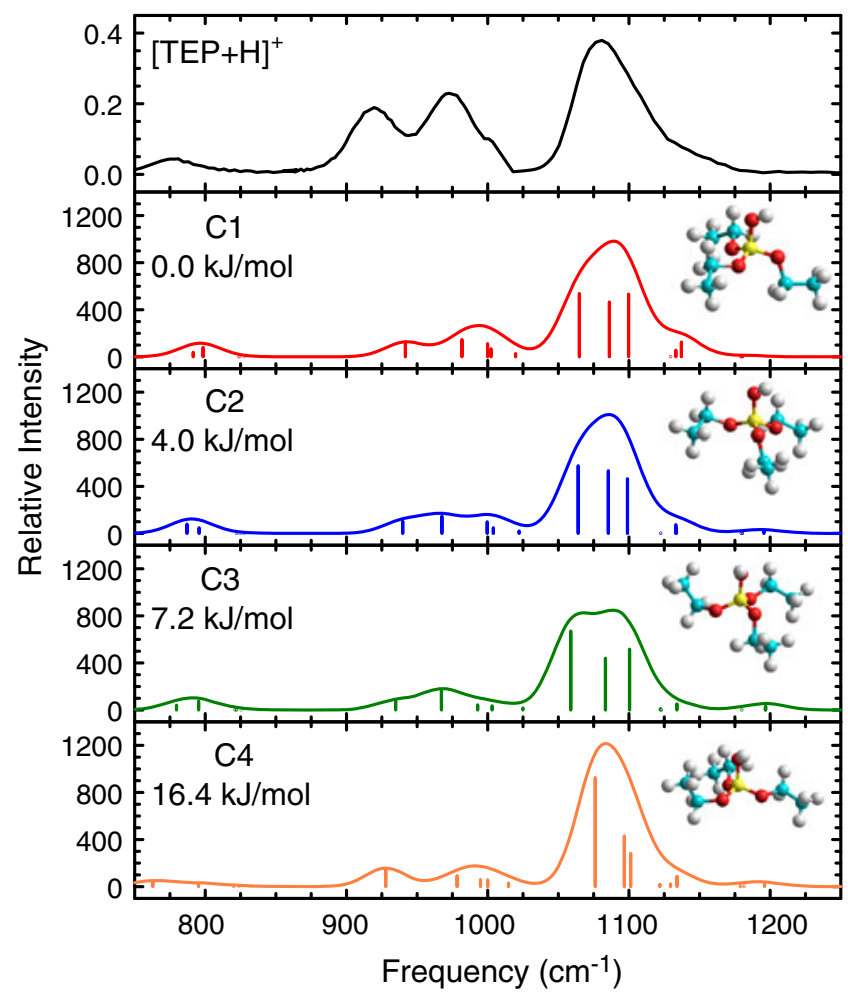

Figure 3. Comparison of the measured IRMPD action spectrum of $[\text { TEP }+\mathrm{H}]^{+}$with the linear IR spectra predicted for the four most stable conformers of $[\mathrm{TEP}+\mathrm{H}]^{+}$at the B3LYP/6-31 G(d,p) level of theory. The structures and MP2 (full)/6-311 + G(2d,2p) relative free energies of each conformer are also shown

tance, but differ in that one of the remaining alkoxy side chains is rotated to varying degrees about the $\angle \mathrm{POCC}$ dihedral angle leading to less ideal $\angle \mathrm{H}^{+} \mathrm{OC}$ angles, and resulting in increases in their free energies of 4.0 and $7.2 \mathrm{~kJ} / \mathrm{mol}$ (MP2), respectively. Conformer $\mathrm{C} 4$ does not share these well-ordered geometric features, instead displaying less symmetric $\angle \mathrm{POCC}$ bond angles without regard to the location of the hydroxyl oxygen atoms and a larger $\angle \mathrm{H}^{+} \mathrm{OPO}$ dihedral angle $\left(56.2^{\circ}\right)$ and thus less hydrogen bond stabilization, which is reflected in the relative energy of this conformer, $16.4 \mathrm{~kJ} / \mathrm{mol}$ (MP2).

\section{$[\mathrm{TEP}+\mathrm{Na}]^{+}$}

Binding of a sodium cation to TEP results in a significant increase in the definition of the potential energy surface. While a variety of conformers lie within a narrow energy range for neutral and protonated TEP, fewer conformers exist for the sodium cationized TEP complex. In this case, three conformers are found, two low-energy bidentate conformers (B1 and B2), and a third, higher energy monodentate conformer (M1) as shown in Figure 4 and Figure $3 \mathrm{~S}$ of the Supplementary Information. In the groundstate conformer, B1, the sodium cation interacts with the oxo and one of the alkoxy oxygen atoms with $\mathrm{Na}^{+}-\mathrm{O}$ bond

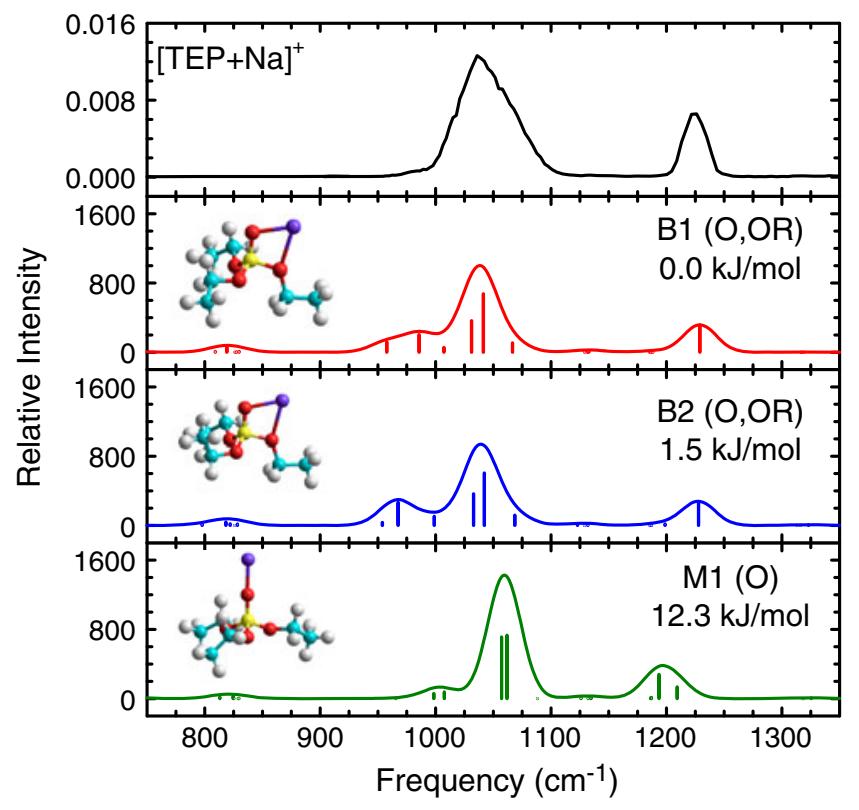

Figure 4. Comparison of the measured IRMPD action spectrum of $\left[\mathrm{TEP}+\mathrm{Na}^{+}\right.$with the linear IR spectra predicted for the three most stable conformers of $[\mathrm{TEP}+\mathrm{Na}]^{+}$at the B3LYP/6-31 G(d,p) level of theory. The structures and MP2 (full)/6-311 + G(2d,2p) relative free energies of each conformer are also shown

distances of 2.182 and $2.489 \AA$, respectively. The sodium bound alkoxy chain is oriented down and away from the metal cation resulting in $\angle \mathrm{OPOC}$ and $\angle \mathrm{Na}^{+} \mathrm{OPO}$ dihedral angles of $177.8^{\circ}$ and $5.1^{\circ}$, respectively, with the free alkoxy chains staggered around the phosphate group, similar to the $\mathrm{C} 1$ conformer of $[\mathrm{TEP}+\mathrm{H}]^{+}$. The $\mathrm{B} 2$ conformer, which lies $1.5 \mathrm{~kJ} / \mathrm{mol}$ (MP2) higher in free energy, is obtained by rotating one of the dihedral $\angle \mathrm{POCC}$ angles by $81.7^{\circ}$. This minor change alters the $\mathrm{Na}^{+}-\mathrm{O}$ bond distances, 2.186 and $2.468 \AA$, and the $\angle \mathrm{OPOC}$ dihedral angle, $177.6^{\circ}$, very little explaining the small difference in energy between the B1 and B2 conformers. The M1 structure, which lies $7.2 \mathrm{~kJ} / \mathrm{mol}$ (MP2) above the ground-state B1 conformer, contains fully staggered alkoxy chains with the sodium cation bound in a monodentate fashion to the oxo oxygen with a $\mathrm{Na}^{+}-\mathrm{O}$ bond distance of $2.081 \AA$, forming a $\angle \mathrm{Na}^{+} \mathrm{OP}$ bond angle of $179.2^{\circ}$.

\section{Discussion}

$[T E P+H]^{+}$

The measured IRMPD action spectrum is compared to the linear IR spectra of the five most energetically favorable conformers computed for the $[\mathrm{TEP}+\mathrm{H}]^{+}$complex in the $750-1250 \mathrm{~cm}^{-1}$ range in Figure 3. When comparing the experimental spectra with the theoretical spectra it is important to note that the theoretical methods produce linear IR spectra (single photon absorption), while the experimental data reflects multiple photon absorption and dissociation by the precursor ion. As a result, the band positions are 
generally reproduced quite well, but the relative intensities of the various bands may not be as a consequence of variations in anharmonic coupling/shifting and the resulting differences in multiple-photon excitation efficiencies [54]. Examination of the figure reveals that the theoretical spectra match the experimental spectrum reasonably well. The high intensity band at $1080 \mathrm{~cm}^{-1}$ represents alkoxy $\mathrm{P}-\mathrm{O}$ stretching. Moderately high intensity bands at 975 and $920 \mathrm{~cm}^{-1}$ correspond to $\mathrm{O}-\mathrm{H}$ wagging and $\mathrm{P}-\mathrm{OH}$ stretching, respectively. Both of these bands also represent a small degree of methyl rocking. A lower intensity band at $780 \mathrm{~cm}^{-1}$ corresponds to $\mathrm{C}-\mathrm{O}$ stretching. The shoulders at 1002 and $1130 \mathrm{~cm}^{-1}$ represents $\mathrm{C}-\mathrm{C}$ stretching and methyl rocking, respectively.

Assignment of the $\mathrm{C} 1$ conformer to the experimental spectra is justified by the shape and location of bands at 1080,975 , and $920 \mathrm{~cm}^{-1}$, and especially by the definition of the bands at 975 and $920 \mathrm{~cm}^{-1}$. The $\mathrm{C} 2$ conformer, lying only $4.0 \mathrm{~kJ} / \mathrm{mol}$ (MP2) higher in free energy than the C1 conformer, is also very similar to the experimental and $\mathrm{C} 1$ spectra, but a less prominent shoulder at $1130 \mathrm{~cm}^{-1}$ and poor definition of the bands at 975 and $920 \mathrm{~cm}^{-1}$ such that $\mathrm{C} 2$ does not match the observed IRMPD spectrum quite as ideally as $\mathrm{C} 1$, but certainly cannot be ruled out. Based on the computed stability, the $\mathrm{C} 2$ conformer is likely a moderate contributor to the measured spectrum. The $\mathrm{C} 3$ conformer lies $7.2 \mathrm{~kJ} / \mathrm{mol}$ (MP2) higher in free energy than the ground-state C1 structure. Sufficient differences between the experimental IRMPD and C3 IR spectra are evident, which makes it unlikely that $\mathrm{C} 3$ is a significant contributor to the observed spectrum. Splitting of the $1080 \mathrm{~cm}^{-1}$ band, further reduction of the $1130 \mathrm{~cm}^{-1}$ shoulder, and merging of the 975 and $920 \mathrm{~cm}^{-1}$ bands into a single band at $967 \mathrm{~cm}^{-1}$, and the computed relative stability all suggest that the $\mathrm{C} 3$ conformer is at best a very minor contributor to the measured IRMPD spectrum. The spectrum corresponding to the $\mathrm{C} 4$ conformer more closely represents the experimental spectrum than $\mathrm{C} 3$, but red shifting of the broad feature at $1080 \mathrm{~cm}^{-1}$ and the absence of the band at $780 \mathrm{~cm}^{-1}$, in addition to the relatively high energy ( $16.4 \mathrm{~kJ} / \mathrm{mol}, \mathrm{MP} 2)$, make the $\mathrm{C} 4$ conformer an unlikely contributor.

\section{$[\mathrm{TEP}+\mathrm{Na}]^{+}$}

The experimental IRMPD and theoretical IR spectra for the $[\mathrm{TEP}+\mathrm{Na}]^{+}$complex are compared in Figure 4. Only two bands are observed, a band at $1038 \mathrm{~cm}^{-1}$ arising from an asymmetric $\mathrm{P}-\mathrm{O}-\mathrm{C}$ stretch, and another at $1225 \mathrm{~cm}^{-1}$ corresponding to the oxo $\mathrm{P}=\mathrm{O}$ stretch. Examination of the theoretical spectra suggests that both bidentate conformers, B1 and B2, contribute significantly to the experimental spectrum. Bands at 1038 and $1225 \mathrm{~cm}^{-1}$ correspond extremely well with the experimental spectrum. A small shoulder at $985 \mathrm{~cm}^{-1}$ in the observed IRMPD spectrum provides the best means of discriminating between the B1 and B2 conformers. A corresponding shoulder at $985 \mathrm{~cm}^{-1}$ is visible in the B1 spectra, but the related band is red shifted to $965 \mathrm{~cm}^{-1}$ in the B2 spectra. This suggests that B1 is the dominant contributing species, but spectral similarities and energetic considerations suggest a measurable B2 population as well. In contrast, the IR spectrum of monodentate M1 differs significantly. The oxo $\mathrm{P}=\mathrm{O}$ band is red shifted from 1225 to $1200 \mathrm{~cm}^{-1}$, while the asymmetric $\mathrm{P}-\mathrm{O}-\mathrm{C}$ stretch is blue shifted from 1038 to $1060 \mathrm{~cm}^{-1}$. These spectral differences, in addition to the relatively high energy $(12.3 \mathrm{~kJ} / \mathrm{mol}$, MP2), suggest that if present, the M1 conformer is only a very minor contributor to the measured IRMPD spectrum.

\section{Theoretical System: TEP}

While experimental data corresponding to the neutral TEP system cannot be obtained using the experimental methods employed here, theoretical studies produce data that can provide insight into cellular nucleic acid systems. Figure 2 depicts the five lowest energy conformers determined from our theoretical search, while Table 2 describes changes in the computed frequencies of the observed bands. Because all five conformers lie within $5.0 \mathrm{~kJ} / \mathrm{mol}$ of the ground-state conformer (MP2), each structure can be expected to contribute to a room temperature distribution. This hypothesis is supported by the IR spectra predicted for TEP, as features present in the ground-state spectrum are maintained with little variation throughout for all five conformers. The high intensity band at $1061 \mathrm{~cm}^{-1}$ represents symmetric and asymmetric $\mathrm{C}-\mathrm{O}$ stretching. The position of this band remains essentially unchanged for all five conformers. The band at $981 \mathrm{~cm}^{-1}$, corresponding to alkoxy $\mathrm{P}-\mathrm{O}$ stretching, is a more interesting case, as this band becomes increasingly red-shifted from 981 to $963 \mathrm{~cm}^{-1}$ as the energy of the conformers increases from 0.0 to $5.0 \mathrm{~kJ} / \mathrm{mol}$ (MP2). Similarly, the band arising from the $\mathrm{C}-\mathrm{H}$ wag at $822 \mathrm{~cm}^{-1}$ is increasingly red-shifted as energy increases from $\mathrm{C} 1$ to C5. The low intensity feature at $538 \mathrm{~cm}^{-1}$, representing a $\mathrm{P}-\mathrm{O}$ rock, is also increasingly red-shifted from the $\mathrm{C} 1$ to $\mathrm{C} 4$ conformers, but deviates from this trend for the $\mathrm{C} 5$ conformer, which appears at $531 \mathrm{~cm}^{-1}$ similar to those of $\mathrm{C} 2$ and $\mathrm{C} 3$ rather than continuing to follow the trend and be found below $523 \mathrm{~cm}^{-1}$. In contrast, the oxo $\mathrm{P}=\mathrm{O}$ stretch at $1285 \mathrm{~cm}^{-1}$ does not seem to follow any particular trend. Instead, values vary from 1276 to $1309 \mathrm{~cm}^{-1}$. While some variation in frequencies is observed between the described spectral features, no appreciable difference in the band intensities is observed for all five conformers.

Structures and spectra were reported by Groenewold and coworkers for the neutral TEP system as previously mentioned [50]. To provide a useful evaluation of the results of their work, an IR spectrum of neat TEP from the National Institute of Standards and Technology (NIST) spectral database [55] was compared with a DFT predicted spectra [B3LYP/6-311++g(3df, 2pd)] that accounted for solvent effects through the use of the integral-equation-formalism 
Table 2. Progression of Spectroscopic Features for Neutral TEP ${ }^{\mathrm{a}}$

\begin{tabular}{lcccr}
\hline \multirow{2}{*}{ Stretching mode } & \multicolumn{3}{c}{ Conformer } \\
\cline { 2 - 5 } & C1 & C2 & C3 & C4 \\
\hline P=O rock & 538 & 532 & 531 & 523 \\
C-H wag & 822 & 819 & 820 & 815 \\
Alkoxy P-O stretch & 981 & 975 & 975 & 963 \\
C-O stretch & 1061 & 1061 & 1061 & 1061 \\
P=O stretch & 1285 & 1282 & 1309 & 1276 \\
\hline
\end{tabular}

${ }^{\mathrm{a}}$ Frequencies in $(\mathrm{cm}-1)$ predicted at the B3LYP/6-31 G(d,p) level of theory

polarizable continuum model (IEFPCM). Reasonably good correlation was observed between experiment and theory even without scaling of the predicted spectrum. The groundstate structure of TEP determined using the IEFPCM model differs from the $\mathrm{C} 1$ conformer found here in vacuum. The structure determined by Groenewold and coworkers is most similar to the $\mathrm{C} 3$ confomer determined here, which differs from $\mathrm{C} 1$ via rotation of the $\angle \mathrm{OPOC}$ dihedral angle by $133.9^{\circ}$ and lies $2.6 \mathrm{~kJ} / \mathrm{mol}$ higher in free energy (MP2). Spectral differences between the $\mathrm{C} 1$ and $\mathrm{C} 3$ conformers are minor, such that comparisons with the NIST spectral data remain unaffected for gas phase and neat structures.

To provide an additional means for verification of the accuracy of the theoretical TEP structures, the gas phase IR spectrum recently added in the National Institute of Standards and Technology (NIST) spectral database [55] is compared with conformers $\mathrm{C} 1-\mathrm{C} 5$ in Figure 2. A remarkable level of congruency exists between the DFT linear IR spectra and the NIST spectrum, both in the relative intensity and the positioning of bands. Features are maintained especially well between the $\mathrm{C} 1$ conformer and the NIST spectra. Bands previously described at 538, 822, 981, 1061, and $1285 \mathrm{~cm}^{-1}$ for $\mathrm{C} 1$ correspond to NIST bands at 532, 812, 967, 1045, and $1282 \mathrm{~cm}^{-1}$. Strong correlation between related bands of the two spectra provide strong support for the DFT methods used in this and other related studies.

\section{Effects of Protonation on Spectra and Structure}

Addition of a proton to the neutral TEP molecule produces distinct spectral and geometric changes. Spectral features of TEP are compared to those of $[\text { TEP }+\mathrm{H}]^{+}$and $[\text { TEP }+\mathrm{Na}]^{+}$in Figure 1. Prominent shifting of spectral features include movement of the $\mathrm{P}-\mathrm{O}$ alkoxy stretch from 967 to $1080 \mathrm{~cm}^{-1}$, and of the $\mathrm{C}-\mathrm{O}$ stretch from 1045 to $780 \mathrm{~cm}^{-1}$. Several features disappear as a result of proton binding, most notably $\mathrm{P}=\mathrm{O}$ related features including stretching and rocking modes at 1282 and $532 \mathrm{~cm}^{-1}$, respectively, that are present in the neutral system. Associated electronic and structural changes include increasing $\mathrm{P}-\mathrm{O}$ bond hybridization, and changes to $\angle \mathrm{OPO}$ bond angles and $\mathrm{P}-\mathrm{O}$ bond lengths. An increase in the $\angle \mathrm{OPO}$ bond angle from $101.9^{\circ}$ to $107.4^{\circ}$, accompanied by a decrease in alkoxy $\mathrm{P}-\mathrm{O}$ bond length from 1.61 to $1.56 \AA$, occurs with protonation. In the context of a nucleic acid these changes may play a significant role in the overall structure of the macromolecular system. While the resulting $\mathrm{O}-\mathrm{O}$ separation of adjacent alkoxy chains remains nearly constant (2.50 to $2.51 \AA$ ), the central phosphorous atom, as well as the entire phosphate moiety, moves closer to the hypothetical axis created by the previously mentioned $\mathrm{O}-\mathrm{O}$ atoms. Electronic interactions between the phosphate and other nucleic acid components, such as ribose sugars or nucleobases, may also play a role in the overall effects of nucleic acid protonation, but their effects are the subject of other studies currently being pursued in our laboratory.

\section{Effects of Sodium Cationization on Spectra and Structure}

Similar to the case of protonation, sodium cationization produces changes in both spectral and geometric features of TEP. In the case of sodium metal cationization, spectral changes are far more significant than structural ones. The $[\mathrm{TEP}+\mathrm{Na}]^{+}$spectrum appears simple compared with the feature-rich spectrum of neutral TEP, and both are displayed in Figure 1. Bands at 532 and $812 \mathrm{~cm}^{-1}$ of TEP, corresponding to $\mathrm{P}-\mathrm{O}$ rocking and $\mathrm{C}-\mathrm{H}$ wagging, have no corresponding bands in the $[\mathrm{TEP}+\mathrm{Na}]^{+}$ spectrum. One of the retained features, a $\mathrm{C}-\mathrm{O}$ stretch, manifests itself as a single, broad feature at $1038 \mathrm{~cm}^{-1}$ that results from a combination of a blue shift from $967 \mathrm{~cm}^{-1}$ and a red shift from $1045 \mathrm{~cm}^{-1}$ of the TEP bands. Linear IR spectra suggest that this broad band is the result of three unresolved bands in close proximity, arising from the three $\mathrm{C}-\mathrm{O}$ stretching modes. The second retained feature, a low intensity band corresponding to $\mathrm{P}=$ $\mathrm{O}$ stretching, red shifts from 1282 to $1225 \mathrm{~cm}^{-1}$ upon addition of a sodium cation to TEP, producing [TEP + $\mathrm{Na}]^{+}$. Structural changes resulting from sodium cation binding are less pronounced than those of proton binding to TEP. The $\angle \mathrm{OPO}$ bond angles increase upon $\mathrm{Na}^{+}$ binding, from $101.9^{\circ}$ to $104.3^{\circ}$. As with $[\mathrm{TEP}+\mathrm{H}]^{+}, \mathrm{P}-\mathrm{O}$ bond length also decreases, but to a lesser extent, from 1.61 to $1.58 \AA$ (versus $1.56 \AA$ for protonation). Also 
similar to changes associated with the protonated [TEP + $\mathrm{H}^{+}$system, the distance between adjacent oxygen atoms changes negligibly, with both TEP and [TEP $+\mathrm{Na}]^{+}$ having an $\mathrm{O}-\mathrm{O}$ distance of $2.50 \AA$.

\section{Comparison of the Effects of Sodium and Potassium Cationization on Spectra}

The spectral features observed in the IRMPD spectrum of $[\mathrm{TEP}+\mathrm{Na}]^{+}$differ from those observed for $[\mathrm{TEP}+\mathrm{K}]^{+}$by Groenewold and coworkers in a systematic fashion [50]. Resolution of vibrational bands in [TEP $+\mathrm{K}]^{+}$is superior to those of $[\mathrm{TEP}+\mathrm{Na}]^{+}$due to inherent broadening characteristics of adjacent bands, especially those bands corresponding to $\mathrm{C}-\mathrm{O}$ stretching. Two distinct $\mathrm{C}-\mathrm{O}$ bands are observed for $[\text { TEP }+\mathrm{K}]^{+}$, at 980 and $1040 \mathrm{~cm}^{-1}$, while only a single corresponding band at $1038 \mathrm{~cm}^{-1}$ was observed for [TEP + $\mathrm{Na}]^{+}$. Theoretical linear IR spectra show that this broad feature at $1038 \mathrm{~cm}^{-1}$ arises from three separate bands, at 1026,1038 , and $1063 \mathrm{~cm}^{-1}$, each corresponding to a $\mathrm{C}-\mathrm{O}$ stretch for the three different alkoxy groups. Their close proximity results in observation of a single, broadened feature in the IRMPD action spectrum. The $\mathrm{P}=\mathrm{O}$ band of TEP at $1282 \mathrm{~cm}^{-1}$ is red shifted for both the $[\text { TEP }+\mathrm{Na}]^{+}$ and $[\text { TEP }+\mathrm{K}]^{+}$complexes, however, the magnitude of the shift is larger for the more strongly bound $\mathrm{Na}^{+}$than $\mathrm{K}^{+}$, as this band appears at 1225 and $1235 \mathrm{~cm}^{-1}$, respectively.

\section{TEP versus DEP}

Previously, we investigated the effects of both protonation and sodium cationization on the structure of DEP [37]. While DEP is a superior model for typical nucleic acids, TEP provides an excellent model for certain alkylated nucleic acids, such as those found in mutated states [4749]. Variations between the two systems are notable with sodium cationization, though effects due to protonation differ little between TEP and DEP. Protonation results in a significant increase in the alkoxy $\angle \mathrm{OPO}$ bond angle for both TEP $\left(101.9^{\circ}-107.4^{\circ}\right)$ and DEP $\left(101.4^{\circ}-108.4^{\circ}\right)$. Sodium cationization, however, produces a smaller change in the alkoxy $\angle \mathrm{OPO}$ angle for TEP $\left(101.9^{\circ}-104.3^{\circ}\right)$, and no noticeable change in the DEP system. Protonation produces greater change than sodium cationization in both TEP and DEP systems, likely due to its smaller size and subsequent ability to very strongly interact with the phosphate moiety and thus form a covalent rather than noncovalent bond. Variation between DEP and TEP can be explained by consideration of the presence of the additional alkoxy chain in TEP. Protons are able to interact reasonably well with both DEP and TEP due to their small size, with few differences due to the additional alkoxy chain of TEP. In the case of sodium cationization, however, spatial considerations become more important. Interaction between the sodium cation and the additional alkoxy chain of TEP results in a modest change in the alkoxy $\angle \mathrm{OPO}$ bond angle $\left(2.4^{\circ}\right)$, while the absence of the corresponding alkoxy chain in the DEP system produces less than a $0.1^{\circ}$ change in the alkoxy $\angle \mathrm{OPO}$ bond angle due to reduced steric and torsional interference.

\section{Conclusions}

Theoretical results clearly demonstrate well-defined structural changes in the geometry of TEP upon both protonation and sodium cationization. The highly symmetrical neutral TEP ligand is a reasonable model for alkylated nucleic acids, and also as a starting point for modifications that result from electrostatic interaction with protons or sodium cations. Sodium cationization results in a bidentate interaction between the metal cation and the TEP ligand due to rotation of one of the alkoxy chains away from the staggered conformation. Similarly, protonation produces a structure with very similar phosphate geometry to that of sodium cationization, suggesting that either cation could have similar mechanistic effects in solution under physiologic conditions. To further extend this work and achieve a detailed understanding of the effects of cationization of phosphate esters and nucleic acids on structure, study of the interaction of TEP and more complex phosphate esters with additional biologically relevant divalent cations, $\mathrm{Mg}^{2+}, \mathrm{Cu}^{2+}$, and $\mathrm{Zn}^{2+}$, is needed.

\section{Acknowledgments}

This work is supported by the National Science Foundation, grants PIRE-0730072 and CHE-0911191. The authors thank Wayne State University C\&IT for computer time. N.O.F. also thanks the WSU Honors program for additional financial support. This work is also part of the research program of FOM, which is financially supported by the Nederlandse Organisatie voor Wetenschappeklijk Onderzoek (NWO). The skillful assistance of the FELIX staff is gratefully acknowledged.

\section{References}

1. Little, D.P., Speir, J.P., Senko, M.W., O'Connor, P.B., McLafferty, F. W.: Infrared Multiphoton Dissociation of Large Multiply Charged Ions for Biomolecule Sequencing. Anal. Chem. 66, 2809-2815 (1994)

2. Woodin, R.L., Bomse, D.S., Beauchamp, J.L.: Multiphoton Dissociation of Molecules with Low Power Continuous Wave Infrared Laser Radiation. J. Am. Chem. Soc. 100, 3248-3250 ( 1978)

3. Bomse, D.S., Woodin, R.L., Beauchamp, J.L.: Molecular Activation with Low-Intensity CW Infrared Laser Radiation. Multiphoton Dissociation of Ions Derived from Diethyl Ether. J. Am. Chem. Soc. 101, 5503-5512 (1979)

4. Eyler, J.R.: Infrared Multiple Photon Dissociation Spectroscopy of Ions in Penning Traps. Mass Spectrom. Rev. 28, 448-467 (2009)

5. Oomens, J., Steill, J.D.: The Structure of Deprotonated Tri-Alanine and Its a ${ }^{-}$Fragment Anion by IR Spectroscopy. J. Am. Soc. Mass Spectrom. 21, 698-706 (2010)

6. Contreras, C.S., Polfer, N.C., Chung, A.C., Oomens, J., Eyler, J.R.: Hydrogen/Deuterium Exchange of Phenylalanine Analogs Studied with Infrared Multiple Photon Dissociation. Int. J. Mass Spectrom. 297, 162169 (2010) 
7. O'Brien, J.T., Prell, J.S., Berden, G., Oomens, J., Williams, E.R.: Effects of Anions on the Zwitterion Stability of Glu, His, and Arg Investigated by IRMPD Spectroscopy and Theory. Int. J. Mass Spectrom. 297, 116-123 (2010)

8. Dunbar, R.C., Steill, J.D., Oomens, J.: Conformations and Vibrational Spectroscopy of Metal-Ion/Polyalanine Complexes. Int. J. Mass Spectrom. 297, 107-115 (2010)

9. Oomens, J., Moehlig, A.R., Morton, T.H.: Infrared Multiple Photon Dissociation (IRMPD) Spectroscopy of the Proton-Bound Dimer of 1Methylcytosine in the Gas Phase. J. Phys. Chem. Lett. 1, 2891-2897 (2010)

10. Osburn, S., Steill, J.D., Oomens, J., O’Hair, R.A.J., van Stipdonk, M., Ryzhov, V.: Structure and Reactivity of the Cysteine Methyl Ester Radical Cation. Chem. Eur. J. 17, 873-879 (2011)

11. Lagutschenkov, A., Langer, J., Berden, G., Oomens, J., Dopfer, O.: Infrared Spectra of Protonated Neurotransmitters: Dopamine. Phys. Chem. Chem. Phys. 13, 2815-2823 (2011)

12. Dunbar, R.C., Steill, J.D., Oomens, J.: Chirality-Induced Conformational Preferences in Peptide-Metal Ion Binding by IR Spectroscopy. $J$. Am. Chem. Soc. 133, 1212-1215 (2011)

13. Steill, J.D., Szczepanski, J., Oomens, J., Eyler, John R., Brajter-Toth, A.: Structural Characterization by Infrared Multiple Photon Dissociation Spectroscopy of Protonated Gas-Phase Ions Obtained by Electrospray Ionization of Cysteine and Dopamine. Anal. Bioanal. Chem. 399, 2463$2473(2011)$

14. Fenn, J.B., Mann, M., Meng, C.K., Wong, S.F., Whitehouse, C.M.: Electrospray Ionization for Mass Spectrometry of Large Biomolecules. Science 246, 64-71 (1989)

15. Hillenkamp, F., Karas, M., Beavis, R.C., Chait, B.T.: Matrix-Assisted Laser Desorption/Ionization Mass Spectrometry of Biopolymers. Anal. Chem. 63, 1193A-1203A (1991)

16. Valle, J.J., Eyler, J.R., Oomens, J., Moore, D.T., van der Meer, A.F.G., von Heldon, G., Meijer, G., Hendrickson, C.L., Marshall, A.G., Blakney, G.T.: Free Electron Laser-Fourier Transform Ion Cyclotron Resonance Mass Spectrometry Facility for Obtaining Infrared Multiphoton Dissociation Spectra of Gaseous Ions. Rev. Sci. Instrum. 76, 023103 (2005)

17. Polfer, N.C., Oomens, J., Moore, D.T., von Helden, G., Meijer, G., Dunbar, R.C.: Infrared Spectroscopy of Phenylalanine $\mathrm{Ag}(\mathrm{I})$ and $\mathrm{Zn}(\mathrm{II})$ Complexes in the Gas Phase. J. Am. Chem. Soc. 128, 517-525 (2006)

18. Polfer, N.C., Oomens, J.: Reaction Products in Mass Spectrometry Elucidated with Infrared Spectroscopy. Phys. Chem. Chem. Phys. 9, 3804-3817 (2007)

19. Oepts, D.; van der Meer, A.F.G., van Amersfoort, P.W.: The FreeElectron-Laser User Facility FELIX. Infrared Phys. Technol. 36, 297 308 (1995)

20. Armentrout, P.B., Rodgers, M.T., Oomens, J., Steill, J.D.: Infrared Multiphoton Dissociation Spectroscopy of Cationized Serine: Effects of Alkali-Metal Cation Size on Gas Phase Conformation. J. Phys. Chem. A 112, 2248-2257 (2008)

21. Rodgers, M.T., Armentrout, P.B., Oomens, J., Steill, J.D.: Infrared Multiphoton Dissociation Spectroscopy of Cationized Threonine: Effects of Alkali-Metal Cation Size on Gas Phase Conformation. $J$. Phys. Chem. A 112, 2258-2267 (2008)

22. Correia, C.F., Balaj, P.O., Scuderi, D., Maitre, P., Ohanessian, G.: Vibrational Signatures of Protonated, Phosphorylated Amino Acids in the Gas Phase. J. Am. Chem. Soc. 130, 3359-3370 (2008)

23. Polfer, N.C., Oomens, J., Dunbar, R.C.: Alkali Metal Complexes of the Dipeptides PheAla and AlaPhe: IRMPD Spectroscopy. Chem. Phys. Chem. 9, 579-589 (2008)

24. O’Brien, J.T., Prell, J.S., Steill, J.D., Oomens, J., Williams, E.R.: Interactions of Mono- and Divalent Metal Ions with Aspartic and Glutamic Acid Investigated with IR Photodissociation Spectroscopy and Theory. J. Phys. Chem. A 112, 10823-10830 (2008)

25. Bush, M.F., Oomens, J., Williams, E.R.: Proton Affinity and Zwitterion Stability: New Results from Infrared Spectroscopy and Theory of Cationized Lysine and Analogues in the Gas Phase. J. Phys. Chem. A 113, 431-438 (2009)

26. Prell, J.S., Demireva, M., Oomens, J., Williams, E.R.: Role of Sequence in Salt-Bridge Formation for Alkali Metal Cationized GlyArg and ArgGly Investigated with IRMPD Spectroscopy and Theory. J. Am. Chem. Soc. 131, 1232-1242 (2009)

27. Scuderi, D., Correia, C.F., Balaj, P.O., Ohanessian, G., Lemaire, J., Maitre, P.: Structural Characterization by IRMPD Spectroscopy and
DFT Calculations of Deprotonated Phosphorylated Amino Acids in the Gas Phase. Chem. Phys. Chem. 10, 1630-1641 (2009)

28. Heaton, A.L., Bowman, V.N., Oomens, J., Steill, J.D., Armentrout, P. B.: Infrared Multiple Photon Dissociation Spectroscopy of Cationized Asparagine: Effects of Metal Cation Size on Gas-Phase Conformation. J. Phys. Chem. A 113, 5519-5530 (2009)

29. Dunbar, R.C., Steill, J.D., Polfer, N.C., Oomens, J.: Gas-Phase Infrared Spectroscopy of the Protonated Dipeptides $\mathrm{H}^{+}$PheAla and $\mathrm{H}^{+}$AlaPhe Compared to Condensed-Phase Results. Int. J. Mass Spectrom. 283, 7784 (2009)

30. Dunbar, R.C., Hopkinson, A.C., Oomens, J., Siu, C.-K., Siu, K.W.M., Steill, J.D., Verkerk, U.H., Zhou, J.: Conformation Switching in GasPhase Complexes of Histidine with Alkaline Earth Ions. J. Phys. Chem. B 113, 10403-10408 (2009)

31. Dunbar, R.C., Steill, J., Polfer, N.C., Oomens, J.: Peptide Length, Steric Effects and Ion Solvation Govern Zwitterion Stabilization in BariumChelated Di- and Tripeptides. J. Phys. Chem. B 113, 10552-10554 (2009)

32. Prell, J.S., O'Brien, J.T., Steill, J.D. Oomens, J., Williams, E.R. Structures of Protonated Dipeptides: The Role of Arginine in Stabilizing Salt Bridges. J. Am. Chem. Soc. 131, 11442-11449 (2009)

33. Prell, J.S., Flick, T.G., Oomens, J., Berden, G., Williams, E.R.: Coordination of Trivalent Metal Cations to Peptides: Results from IRMPD Spectroscopy and Theory. J. Phys. Chem. A 114, 854-860 (2009)

34. Armentrout, P.B., Carl, D.R., Cooper, T.E., Oomens, J., Steill, J.D.: Infrared Multiple Photon Dissociation Spectroscopy of Cationized Methionine: Effects of Alkali-Metal Cation Size on Gas-Phase Conformation. Phys. Chem. Chem. Phys. 12, 3384-3398 (2010)

35. Citir, M., Stennett, E.M.S., Oomens, J., Steill, J.D., Rodgers, M.T., Armentrout, P.B.: Infrared Multiple Photon Dissociation Spectroscopy of Cationized Cysteine: Effects of Metal Cation Size on Gas-Phase Conformation. Int. J. Mass Spectrom. 297, 9-17 (2010)

36. Dray, M.K., Armentrout, P.B., Oomens, J., Schafer, M.: IR Spectroscopy of Cationized Aliphatic Amino Acids: Stability of ChargeSolvated Structure Increases with Metal Cation Size. Int. J. Mass Spectrom. 297, 18-27 (2010)

37. Fales, B.S., Fujamade, N.O., Nei, Y.-w., Oomens, J., Rodgers, M.T.: Infrared Multiple Photon Dissociation Action Spectroscopy and Theoretical Studies of Diethyl Phosphate Complexes: Effects of Protonation and Sodium Cationization on Structure. J. Am. Soc. Mass Spectrom. 22, 81-92 (2011)

38. Ruan, C., Huang, H., Rodgers, M.T.: Modeling Metal Cation-Phosphate Interactions in Nucleic Acids in the Gas Phase via Alkali Metal CationTriethyl Phosphate Complexes. J. Phys. Chem. A 111, 13521-13527 (2007)

39. Ruan, C., Rodgers, M.T.: Modeling Metal Cation-Phosphate Interactions in Nucleic Acids: Activated Dissociation of $\mathrm{Mg}^{+}, \mathrm{Al}^{+}, \mathrm{Cu}^{+}$, and $\mathrm{Zn}^{+}$Complexes of Triethyl Phosphate. J. Am. Chem. Soc. 131, 1091810928 (2009)

40. Ruan, C.; Huang, H., Rodgers, M.T.: A Simple Model for Metal CationPhosphate Interactions in Nucleic Acids in the Gas Phase: Alkali Metal Cations and Trimethyl Phosphate. J. Am. Soc. Mass Spectrom. 19, 305314 (2008)

41. Yang, Z., Rodgers, M.T.: Influence of Methylation on the Properties of Uracil and its Noncovalent Interactions with Alkali Metal Ions. Threshold Collision-Induced Dissociation and Theoretical Studies. Int. J. Mass Spectrom. 241, 225-242 (2005)

42. Yang, Z., Rodgers, M.T.: Influence of Thioketo Substitution on the Properties of Uracil and its Noncovalent Interactions of Uracil with Alkali Metal Ions. Threshold Collision-Induced Dissociation and Theoretical Studies. J. Phys. Chem. A 110, 1455-1468 (2006)

43. Yang, Z., Rodgers, M.T.: Influence of Halogenation on the Properties of Uracil and its Noncovalent Interactions with Alkali Metal Ions. Threshold Collision-Induced Dissociation and Theoretical Studies. J. Am. Chem. Soc. 126, 16217-16226 (2004)

44. Nei, Y.-w., Akinyemi, T.E., Steill, J.D., Oomens, J., Rodgers, M.T.: Infrared Multiple Photon Dissociation Action Spectroscopy of Protonated Uracil and Thiouracils: Effects of Thioketo Substitution on GasPhase Conformation. Int. J. Mass Spectrom. 297, 139-151 (2010)

45. Nei, Y.-w., Akinyemi, T.E., Kaczan, C.M., Steill, J.D., Berden, G., Oomens, J., Rodgers, M.T.: Infrared Multiple Photon Dissociation Action Spectroscopy of Sodiated Uracil and Thiouracils: Effects of Thioketo-substitution on Gas-Phase Conformation. Int. J. Mass Spectrom. (2011). doi:10.1016/j.ijms.2011.06.019 
46. Kaczan, C.M., Rathur, A.I., Wu, R.R., Chen, Y., Austin, C.A., Oomens, J. Berden, G., Rodgers, M.T.: Infrared Multiple Photon Dissociation Action Spectroscopy of Sodium Cationized Halouracils: Effects of Halogenation on Gas-Phase Conformation. J. Am. Soc. Mass Spectrom. manuscript in preparation

47. Singer, B., Grunberger, D.: Molecular Biology of Mutagens and Carcinogens: Reactions of Directly Acting Agents with Nucleic Acids, pp. 45-96. Plenum Press: New York, NY (1983)

48. Skibo, E.B., Schulz, W.G.: Pyrrolo[1,2-a]Benzimidazole-Based Aziridinyl Quinones. A New Class of DNA Cleaving Agent Exhibiting G and A Base Specificity. J. Med. Chem. 36, 30503055 (1993)

49. Schulz, W.G., Nieman, R.A., Skibo, E.B.: Evidence for DNA Phosphate Backbone Alkylation and Cleavage by Pyrrolo[1, 2-a] benzimidazoles: Small Molecules Capable of Causing Base-PairSpecific Phosphodiester Bond Hydrolysis. Proc. Natl. Acad. Sci. U.S.A. 92, 11854-11858 (1995)

50. Groenewold, G.S., Leavitt, C.M., Dain R.P., Oomens, J., Steill, J.D., van Stipdonk, M.J.: Infrared Spectrum of Potassium-Cationized Triethylphosphate Generated Using Tandem Mass Spectrometry and Infrared Multiple Photon Dissociation. Rapid Commun. Mass Spectrom. 23, 2706-2710 (2009)

51. George, L., Sankaran, K., Viswanathan, K.S., Mathews, C.K.: A Matrix-Isolation Infrared Study of the Adducts of Triethyl Phosphate with $\mathrm{CCl}_{4}, \mathrm{CHCl}_{3}$ and $\mathrm{CH}_{2} \mathrm{Cl}_{2}$. Spectrochim. Acta. 51A, 587-593 (1995)
52. HyperChem Computational Chemistry Software Package, Version 5.0; Hypercube Inc: Gainesville, FL (1997)

53. Frisch, M.J., Trucks, G.W., Schlegel, H.B., Scuseria, G.E., Robb, M.A., Cheeseman, J.R., Montgomery, J.A. Jr., Vreven, T., Kudin, K.N., Burant, J.C., Millam, J.M., Iyengar, S.S., Tomasi, J., Barone, V., Mennucci, B., Cossi, M., Scalmani, G., Rega, N., Petersson, G.A., Nakatsuji, H., Hada, M., Ehara, M., Toyota, K., Fukuda, R., Hasegawa, J., Ishida, M., Nakajima, T., Honda, Y., Kitao, O., Nakai, H., Klene, M., Li, X., Knox, J.E., Hratchian, H.P., Cross, J.B., Adamo, C., Jaramillo, J., Gomperts, R., Stratmann, R.E., Yazyev, O., Austin, A.J., Cammi, R., Pomelli, C., Ochterski, J.W., Ayala, P.Y., Morokuma, K., Voth, G.A., Salvador, P., Dannenberg, J.J., Zakrzerski, V.G., Dapprich, S., Daniels, A.D., Strain, M.C., Farkas, O., Malick, D.K., Rabuck, A.D., Raghavachari, K., Foresman, J.B., Ortiz, J.V., Cui, Q., Baboul, A.G., Clifford, S., Cioslowski, J., Stefanov, B.B., Liu, G., Liashenko, A., Piskorz, P., Komaromi, I., Martin, R.L., Fox, D.J., Keith, T., Al-Laham, M.A., Peng, C.Y., Nanayakkara, A., Challacombe, M., Gill, P.M.W., Johnson, B., Chen, W., Wong, M.W., Gonzalez, C., and Pople. Gaussian 03, Revision B.03, J. A. Gaussian, Inc.: Wallingford, CT (2004)

54. Schermann, J.-P: Spectroscopy and Modeling of Biomolecular Building Blocks; Elsevier, Amsterdam (2008)

55. Infrared Spectra by NIST Mass Spec Data Center, Stein, S. E. Director, in NIST Chemistry WebBook, NIST Standard Reference Database Number 69, Linstrom, P. J.; Mallard, W. G., (Eds). National Institute of Standards, Technology: Gaithersburg, MD 20899, USA. Available at: http://webbook.nist.gov (accessed April 14, 2011). 